\title{
Changes of Peripheral Blood Lymphocyte Subtypes in Patients with End Stage Cancer Administered Localized Radiotherapy and Bojungikki-Tang
}

\author{
A-Jin Lee, ${ }^{1}$ Ho Jun Lee, ${ }^{2}$ Jong-Dae Kim, ${ }^{3}$ Hyun-Jung Jung, ${ }^{4}$ \\ Sung Hwa Bae, ${ }^{5}$ Hun Mo Ryoo, ${ }^{5}$ and Sang-Gyung Kim ${ }^{1,6}$ \\ ${ }^{1}$ Department of Laboratory Medicine, School of Medicine, Catholic University of Daegu, Daegu 705-718, Republic of Korea \\ ${ }^{2}$ Department of Radiotherapy, School of Medicine, Catholic University of Daegu, Daegu 705-718, Republic of Korea \\ ${ }^{3}$ Department of Internal Medicine, College of Korean Medicine, DaeguaHany University, Daegu 712-715, Republic of Korea \\ ${ }^{4}$ Department of Diagnostics, College of Korean Medicine, DaeguaHany University, Daegu 712-715, Republic of Korea \\ ${ }^{5}$ Division of Hematology-Oncology, Department of Internal Medicine, School of Medicine, Catholic University of Daegu, \\ Daegu 705-718, Republic of Korea \\ ${ }^{6}$ Comprehensive Integrated Medicine Institute, Daegu 705-825, Republic of Korea
}

Correspondence should be addressed to Sang-Gyung Kim; sgkim@cu.ac.kr

Received 22 October 2013; Revised 6 January 2014; Accepted 11 January 2014; Published 20 February 2014

Academic Editor: Sunil Kumar Khare

Copyright ( 2014 A-Jin Lee et al. This is an open access article distributed under the Creative Commons Attribution License, which permits unrestricted use, distribution, and reproduction in any medium, provided the original work is properly cited.

Localized radiotherapy (RT) can cause immune dysfunction. Bojungikki-tang is known to restore immune function. We investigated the absolute counts and percentages of peripheral blood (PB) lymphocyte subtypes in end stage cancer patients before and after RT and after oral administration of Bojungikki-tang water extract (BJITE) and to evaluate the changes mediated by RT and BJITE. Absolute counts and percentages of lymphocyte and lymphocyte subsets were determined in whole blood using the TetraONE System (Beckman Coulter, USA). Flow cytometry results were compared before and after RT and after administration of BJITE. Absolute numbers of CD3+, CD4+, and CD8+ T cells and CD19+ B cells decreased significantly after RT $(P<0.05)$. Absolute numbers of CD3-CD56+ cells did not change in both groups. No significant differences were observed in the absolute counts of lymphocyte subtypes before and after administration of BJITE or vitamin group. When BJITE group was compared with vitamin group, absolute numbers of CD19+ B cells increased. RT-induced decrease in T cells and B cells in PB suggests that immune deterioration occurs after RT. Administration of BJITE might be effective in the restoration of number of B cells.

\section{Introduction}

Radiotherapy (RT) can be used to control symptoms of patients with end stage cancer. RT with palliative intent is administered in approximately one-half of cancer patients [1]. The purposes of palliative RT are to decrease symptoms, including pain, bleeding, and obstruction, and to improve the patient's quality of life $[1,2]$. However, there is an adverse effect of palliative RT. It has been demonstrated that localized radiation, even if administered to limited target volume, causes immune dysfunction [3-5].

Bojungikki-tang (Hochuekkito in Japanese and $\mathrm{Bu}-$ zhong-yi-qi-tang in Chinese) is a traditional herbal formula used in Korea, Japan, and China and it is composed of 10 species of medicinal plants. It has been traditionally used to improve severe weakness in Asian countries. Recent studies have demonstrated that Bojungikki-tang water extract (BJITE) has effect on restoring immune function [6] and inducing an increased protection against microbial agents [7]. It is useful not only for an enhancement of natural killer (NK) activity [8] but also for restoration of antitumor T cell response from stress-induced suppression [9]. Bojungikkitang is known to have protective effect of intestine and hematopoietic organs against radiation damage [10]. However, the immunological response of Bojungikki-tang in patients administrated RT has not yet been determined. 
The aims of the present study were to determine the absolute counts and percentages of peripheral blood (PB) lymphocyte subtypes in end stage cancer patients before and after RT and after oral administration of Bojungikki-tang using single-platform technology and to evaluate the changes mediated by RT and Bojungikki-tang.

\section{Methods and Materials}

2.1. Patients. Thirteen patients were enrolled in this single center, randomised controlled study. Patients meeting the following criteria were included: age 40 years or older; ECOG performance score 0-2; end stage cancer; selected for palliative RT. Exclusion criteria were as follows: patients who have been treated with operation, chemotherapy, or curative radiotherapy in the 2 months prior to randomisation; patients with severe hepatic or renal dysfunction (AST $>80 \mathrm{IU} / \mathrm{L}$, ALT $>80 \mathrm{IU} / \mathrm{L}, \mathrm{BUN}>50 \mathrm{mg} / \mathrm{dL}$, and creatinine > $3.4 \mathrm{mg} / \mathrm{dL}$ ); subjects with a history or hypersensitivity to functional foods; women who are pregnant or nursing; patients who are of child bearing age and are not willing to use contraception; patients who have had major surgery in the 3 months prior to randomization; patients with neuropsychiatric disease; patients who have had cardiovascular or cerebrovascular disease during the previous 6 months; patients who have taken drug in the 3 months prior to randomization. All patients had to provide written informed consent before registration and the trial protocol was approved by the Institutional Review Board of Daegu Catholic University Medical Center, Korea.

Eligible patients were randomly assigned $(1: 1)$ to palliative RT with Bojungikki-tang (BJITE group) or palliative RT with vitamin (vitamin group). Table 1 shows the patients' clinical characteristics. All patients except one suffered from metastatic tumor.

2.2. Procedures. All patients were treated with external RT using a linear accelerator with 6 and 10MV (Varian 21EX linear accelerator equipped with standard multileaf collimators) for 2 to 5 weeks. Fractions of 1.5-3.0 Gy were delivered 5 days/wk for a total dose of 30-50 Gy. After completing RT, BJITE group was orally administered $9.0 \mathrm{~g}$ of Bojungikki-tang everyday $(4.5 \mathrm{~g} \times 2)$ throughout the 4 -week period. Bojungikki-tang was manufactured as a spray-dried powder of hot water extract obtained from 10 medical plants composed of Ginseng radix, Atractylodis rhizoma, Astragali radix, Angelicae radix, Aurantii nobilis pericarpium, Zizyphi fructus, Bupleuri radix, Glycyrrhizae radix, Zingiberis rhizoma, and Cimicifugae rhizoma. Placebo (vitamin) group was taken as non-Bojungikki-tang control. Vitamin tablet was Co-Q ten vitaalbu tab (Ilyang Pharmaceutical Co., Korea) containing $280.9 \mathrm{mg}$ ascorbic acid, $2.5 \mathrm{mg}$ cupric oxide, $5 \mathrm{mg} 0.1 \%$ cyanocobalamin, $0.47 \mathrm{mg}$ dried ergocalciferol powder, $20 \mathrm{mg}$ dried retinol acetate powder, $60.8 \mathrm{mg}$ ferrous fumarate, $41.4 \mathrm{mg}$ magnesium oxide, $1.58 \mathrm{mg}$ manganese dioxide, $100 \mathrm{mg}$ nicotinamide, $15 \mathrm{mg}$ pyridoxine hydrochloride, $30 \mathrm{mg}$ riboflavin, $30 \mathrm{mg}$ thiamine nitrate, $60 \mathrm{mg}$ tocopherol acetate $50 \%, 10 \mathrm{mg}$ ubidecarenone, and $1.87 \mathrm{mg}$ zinc oxide. Vitamin was given orally daily throughout
TABLE 1: Patient clinical characteristics.

\begin{tabular}{lcc}
\hline & $\begin{array}{c}\text { Vitamin group } \\
(N=6)\end{array}$ & $\begin{array}{c}\text { BJITE group } \\
(N=7)\end{array}$ \\
\hline Age (range) & $64 \pm 6(54-70)$ & $66 \pm 6(59-76)$ \\
Sex $(\mathrm{f} / \mathrm{m})$ & $3 / 3$ & $3 / 4$ \\
& Esophagus (1) & Lung (3) \\
& Pyriform sinus (1) & Rectum (2) \\
& Breast (1) & Common bile duct (1) \\
Primary site & Liver (1) & Gastrointestine (1) \\
& Ovary (1) & \\
& Uterus (1) & \\
& Bone (1) & Bone (5) \\
& Lymph node (3) & Brain (1) \\
Metastatic tumor & Chest (1) & Liver (1) \\
\end{tabular}

the 4-week period. The administration of any drugs known to affect the host immunity was avoided during this period.

2.3. Blood Collection. Whole blood samples were collected one day before starting RT (Time 0 ), one day after completing RT (Time 1), and four weeks after oral administration of BJITE or vitamin (Time 2) in sterile EDTA vacutainers.

\subsection{Flow Cytometric Immunophenotyping Using Fluoroch-} rome-Conjugated Antibodies. The percentages and absolute lymphocyte counts were determined in whole blood using a standard single-platform technique, the TetraONE System (Beckman Coulter, Miami, USA), based on four-color flow cytometry in the presence of counting beads. The following combinations were used during immunofluorescence analysis: tubel, anti-CD45-FITC/anti-CD4-PE/antiCD8-ECD/anti-CD3-PC5, and tube 2, anti-CD45-FITC/antiCD56-PE/anti-CD19-ECD/anti-CD3-PC5. For each specimen, $100 \mu \mathrm{L}$ of EDTA-anticoagulated blood was added to $10 \mu \mathrm{L}$ of tetraCHROME reagent containing the fourantibody-fluorochrome combinations and incubated for $20 \mathrm{~min}$ at room temperature in a dark room. Specimens were then lysed using the ImmunoPrep Reagent System at the Coulter Multi-Q-Prep Workstation. Immediately prior to analysis, $100 \mu \mathrm{L}$ of Flow-Count Fluorospheres (Beckman Coulter) was added to each tube, and the beads were counted along with cells. The sample acquisition and flow cytometric immunophenotypic analysis were performed on the FCM, Cytomics (Beckman Coulter), with a fully automated software-reagent combination. The identification of lymphocytes by expression of bright CD45 and low side scatter signals was followed by the identification of $\mathrm{T}$ cell subtypes based on the expression of CD3, CD4, and CD8. B cell subsets and natural killer (NK) cell subsets were based on the expression of CD19 and CD3-CD56+, respectively. The absolute count of cells per microliter was obtained by calculating the number of cells counted $\times$ concentration of beads/number of beads counted. 
TABLE 2: Lymphocyte subset counts (cells/ $\mu \mathrm{L}$ ) in the peripheral blood of end stage cancer patients during study period.

\begin{tabular}{|c|c|c|c|c|c|c|c|}
\hline \multirow{2}{*}{ Cell type } & \multirow{2}{*}{ Surface markers } & \multicolumn{2}{|c|}{ Time 0} & \multicolumn{2}{|c|}{ Time 1} & \multicolumn{2}{|c|}{ Time 2} \\
\hline & & BJITE group & Vitamin group & BJITE group & Vitamin group & BJITE group & Vitamin group \\
\hline Total lymphocytes & & $944 \pm 287$ & $707 \pm 328$ & $722 \pm 355$ & $399 \pm 165$ & $1263 \pm 567$ & $572 \pm 261$ \\
\hline T lymphocytes & $\mathrm{CD}^{+}$ & $612 \pm 183$ & $638 \pm 401$ & $406 \pm 240^{*}$ & $284 \pm 84^{*}$ & $772 \pm 331$ & $434 \pm 193$ \\
\hline Helper & $\mathrm{CD} 4^{+}$ & $348 \pm 189$ & $291 \pm 106$ & $227 \pm 180^{*}$ & $144 \pm 47^{*}$ & $381 \pm 233$ & $167 \pm 64$ \\
\hline \multirow[t]{2}{*}{ Cytotoxic } & $\mathrm{CD}^{+}$ & $268 \pm 116$ & $307 \pm 300$ & $157 \pm 98^{*}$ & $128 \pm 58^{*}$ & $342 \pm 169$ & $250 \pm 145$ \\
\hline & $\mathrm{CD}^{+} / \mathrm{CD}^{+}$ratio & $1.58 \pm 1.15$ & $1.33 \pm 0.71$ & $1.71 \pm 1.04$ & $1.51 \pm 1.08$ & $1.36 \pm 1.05$ & $0.81 \pm 0.34$ \\
\hline B lymphocytes & $\mathrm{CD} 19^{+}$ & $92 \pm 63$ & $95 \pm 66$ & $34 \pm 27^{*}$ & $16 \pm 19^{*}$ & $89 \pm 68$ & $33 \pm 28^{*}$ \\
\hline NK cells & $\mathrm{CD} 6^{+}$ & $254 \pm 158$ & $138 \pm 40$ & $291 \pm 322$ & $80 \pm 95$ & $288 \pm 257$ & $136 \pm 128$ \\
\hline
\end{tabular}

${ }^{*} P$ value $<0.05$ was considered statistically significant (Time 0 versus Time 1 and Time 0 versus Time 2 by Wilcoxon's signed rank sum test).

TABLE 3: The percentages of lymphocyte subsets in the peripheral blood of end stage cancer patients during study period.

\begin{tabular}{|c|c|c|c|c|c|c|c|}
\hline \multirow{2}{*}{ Cell type } & \multirow{2}{*}{ Surface markers } & \multicolumn{2}{|c|}{ Time 0} & \multicolumn{2}{|c|}{ Time 1} & \multicolumn{2}{|c|}{ Time 2} \\
\hline & & BJITE group & Vitamin group & BJITE group & Vitamin group & BJITE group & Vitamin group \\
\hline Total lymphocytes & & $12.2 \pm 3.8$ & $11.6 \pm 2.8$ & $10.4 \pm 5.1$ & $10.5 \pm 3.3$ & $17.3 \pm 8.7$ & $14.9 \pm 7.5$ \\
\hline T lymphocytes & $\mathrm{CD}^{+}$ & $61.2 \pm 11.3$ & $70.2 \pm 6.4$ & $62.2 \pm 19.7$ & $76.3 \pm 10.6$ & $64.8 \pm 13.1$ & $71.4 \pm 9.5$ \\
\hline Helper & $\mathrm{CD} 4^{+}$ & $33.0 \pm 14.1$ & $35.1 \pm 7.6$ & $35.9 \pm 18.1$ & $39.4 \pm 11.9$ & $31.3 \pm 7.7$ & $28.8 \pm 7.0$ \\
\hline Cytotoxic & $\mathrm{CD}^{+}$ & $28.4 \pm 13.7$ & $31.1 \pm 11.6$ & $23.3 \pm 7.0$ & $34.3 \pm 17.0$ & $30.6 \pm 13.8$ & $40.3 \pm 15.3$ \\
\hline B lymphocytes & $\mathrm{CD} 9^{+}$ & $8.8 \pm 6.0$ & $10.2 \pm 6.1$ & $5.0 \pm 2.9$ & $4.0 \pm 4.4^{*}$ & $7.2 \pm 3.8$ & $6.1 \pm 5.0^{*}$ \\
\hline NK cells & $\mathrm{CD}_{56}{ }^{+}$ & $25.7 \pm 13.9$ & $17.5 \pm 7.8$ & $30.1 \pm 20.0$ & $16.7 \pm 11.1$ & $24.8 \pm 15.7$ & $20.7 \pm 11.2$ \\
\hline
\end{tabular}

${ }^{*} P$ value $<0.05$ was considered statistically significant (Time 0 versus Time 1 and Time 0 versus Time 2 by Wilcoxon's signed rank sum test).

2.5. Statistical Analysis. The data are presented as mean and SD. Mann-Whitney $U$ test and the chi-square test were used when appropriate to compare distribution of individual variable between groups. Wilcoxon's signed rank sum test was used to compare change of absolute lymphocyte count and lymphocyte subset. The two-sided $P$ values were considered significant at $P<0.05$. SPSS software version 19.0 (SPSS Inc., Chicago, IL) was used for statistical analysis.

\section{Results}

3.1. Percentages and Counts of Total Lymphocytes and Lymphocyte Subsets after Radiotherapy. Using the single-platform technology, we initially compared both the percentages and absolute counts of lymphocyte subsets in all patients. Absolute counts and percentages of lymphocytes and lymphocyte subsets after RT in the BJITE group $(n=7)$ versus vitamin group $(n=6)$ are shown in Tables 2 and 3, respectively. There were no significant changes in total lymphocyte counts or percentages of lymphocytes during period of time in both groups. No significant differences were observed in the percentages of lymphocyte subtypes. However, absolute numbers of CD3+, CD4+, and CD8+ T cells and CD19+ B cells decreased significantly after RT $(P<0.05)$ (Figure 1$)$. Absolute numbers of CD3-CD56+ cells did not change in both groups.

3.2. Effects of BJITE on Total Lymphocytes and Lymphocyte Subsets. Absolute counts and percentages of lymphocytes and lymphocyte subsets after administration of BJITE or vitamin are shown in Tables 2 and 3, respectively. After administration of BJITE, there were no differences in total lymphocyte number and all lymphocyte subsets compared with baseline data. No differences were found, before and after administration of BJITE or vitamin group, in the CD3+, CD4+, and CD8+ T cells as well in of CD56+ cells. However, there were significant differences in CD19+ B cell counts and percentages of CD19 in vitamin group. In vitamin group, the percentages and absolute counts of CD19 cells did not increase compared with baseline status and remained the decreased status.

\section{Discussion}

Bojungikki-tang is known to restore immune functions and to improve anti-tumor activity [11-13]. It is usually indicated for patients with general weakness and anemia. Palliative RT relieves clinical symptoms in advanced cancer patients but it can also cause immunological changes. In the present study, we have investigated the percentages and absolute counts of PB lymphocytes and lymphocyte subtypes in patients with end stage cancer administered localized radiotherapy and Bojungikki-tang.

In our study, total lymphocyte in counts and percentages of lymphocytes did not change after palliative RT in both groups. This is contrast to the results of the earlier study of radiation-induced lymphocytopenia $[3-5,14]$. This is probably due to differences of radiation dose and interval.

Absolute counts of $\mathrm{T}$ cells and B cells declined after localized RT. Absolute counts of NK cells were not affected by RT. Local radiation at therapeutic doses always triggered some activation of the innate and adaptive immune system 


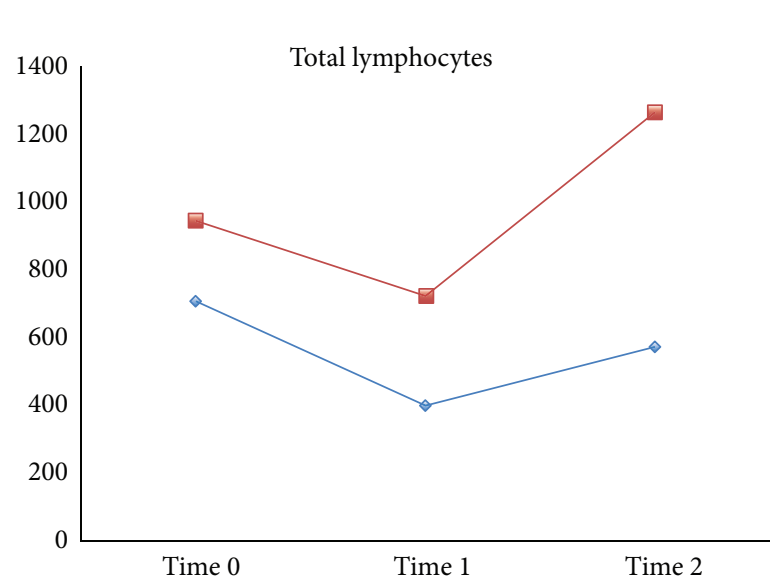

(a)

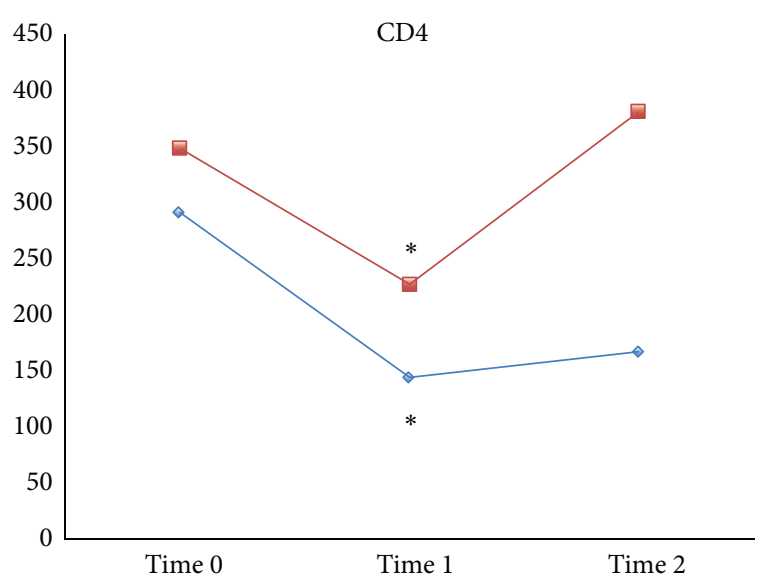

(c)

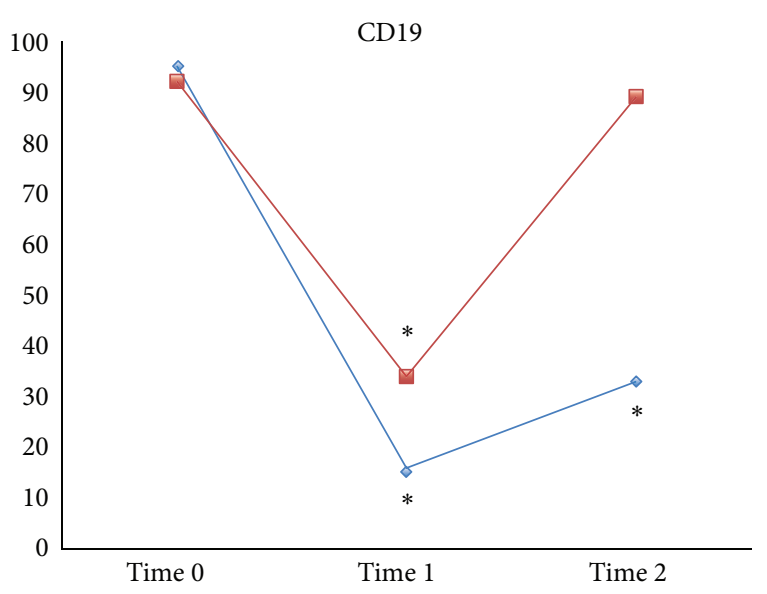

$\diamond-$ Vitamin group
- BJTTE group

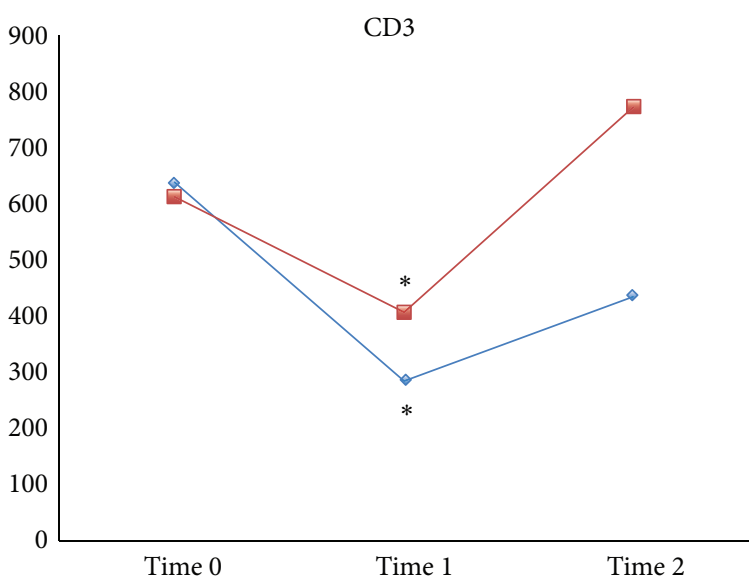

(b)

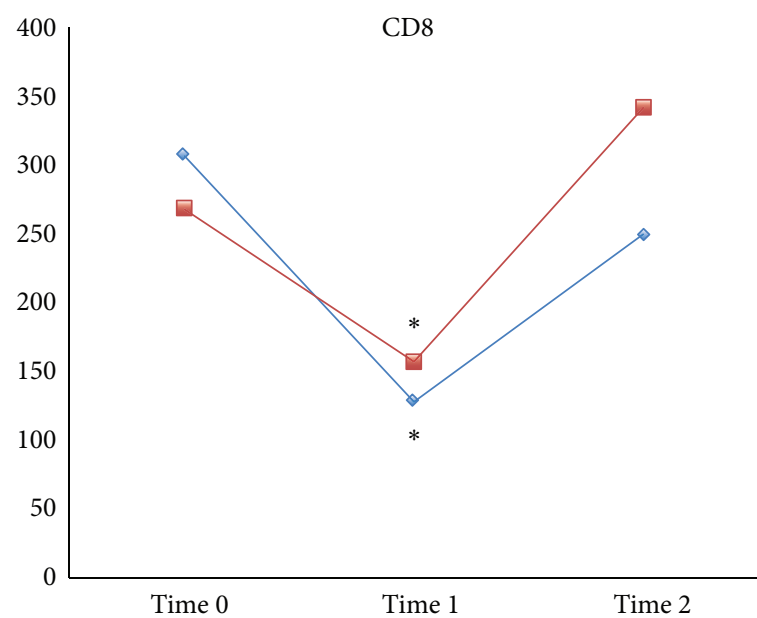

(d)

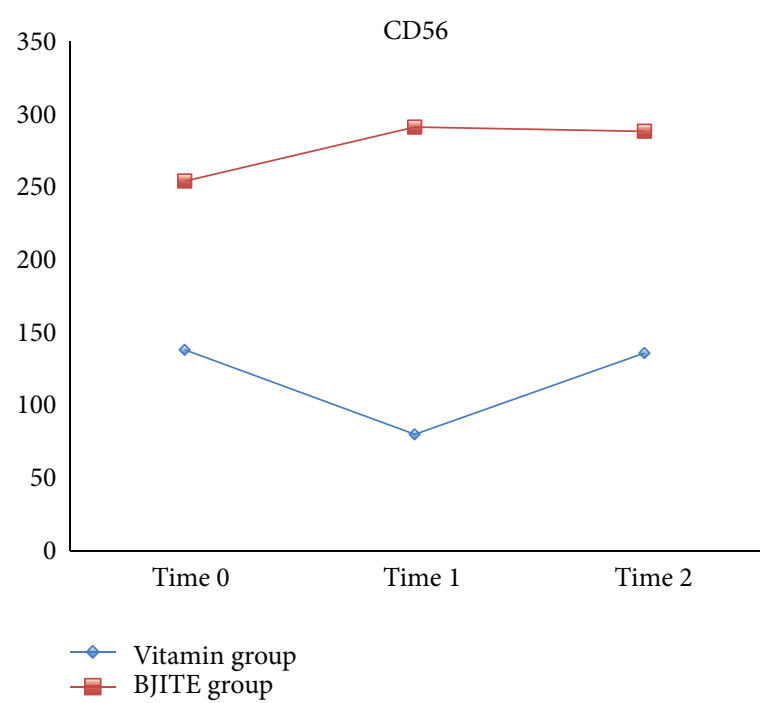

(f)

FIGURE 1: Lymphocyte subset counts during RT in vitamin group versus Bojungikki-tang extract (BJITE) group. 
[15]. Results of present study correspond well with those of the earlier study, which reported that naive T cells and B cells are highly radiosensitive [16, 17]. No significant differences were observed in the percentages of lymphocyte subtypes in all patients. These findings differ from the results of the earlier study, which reported that, unlike absolute numbers, the percentages of all analyzed lymphocyte subsets of cervical cancer patients significantly elevated after RT [18]. Safwat et al. [14] reported that localized RT is associated with a significant increase in the percentage of $\mathrm{CD} 4+\mathrm{T}$ cells and a significant reduction of the absolute number of lymphocyte subsets in patients with non-Hodgkin's lymphoma. This result is similar to our result except for the increase of CD4+ T cell percentages.

Absolute counts of lymphocyte subpopulations in $\mathrm{PB}$ have been traditionally measured by dual-platform technologies, which were standard, widely used methodologies. These methods couple percentages of positive cell subsets determined by flow cytometry with the absolute lymphocyte count obtained by automated hematology analyzers. However, they may be responsible for substantial differences in absolute lymphocyte counts determined by different analyzers [19]. Recently, single-platform technologies were developed and are performed entirely on flow cytometry. These methods have significantly improved the assay precision and accuracy and agreement of results between laboratories $[19,20]$. Using the single-platform flow cytometry, it was possible to independently analyze the percentages and absolute counts of lymphocyte subsets. In this study, absolute counts of lymphocyte subpopulations decreased significantly after RT, although the percentages of lymphocyte subsets did not change. The values of percentages did not consider total WBC count, which might be changed in cancer patients, particularly after administration of RT. Therefore, it may be useful to determine absolute counts, not percentages, of lymphocyte subsets for exactly reflecting immune status of patients.

Absolute counts or percentages of lymphocytes from BJITE or vitamin group showed no significant differences before and after administration of BJITE or vitamin. Another study also reported that the total number of circulating lymphocytes; CD3+, CD4+, and CD8+ T cells; and CD20+ $B$ cells remained unchanged [21].

Interestingly, CD19+ B cells increased significantly after administration of BJITE. These findings are in contrast to the results of the earlier study, which reported that BJITE is remarkably effective in the restoration of number of $\mathrm{T}$ cells and NK cells [8]. Bojungikki-tang is known to have beneficial effects on anti-tumor activity [9] or NK cell activity [21]. In this study, measurement of NK cell activity was not performed. The administration of Bojungikki-tang polysaccharide fraction was associated with elevated expression levels of CD19/CD40 specific for pre-B cells [22].

\section{Conclusions}

In conclusion, RT-induced decrease in helper T cells, cytotoxic $\mathrm{T}$ cells, and $\mathrm{B}$ cells in $\mathrm{PB}$ suggests that immune deterioration occurs after RT. Administration of BJITE might be effective in the restoration of number of B cells.

\section{Conflict of Interests}

The authors declare that there is no conflict of interests regarding the publication of this paper.

\section{Authors' Contribution}

A-Jin Lee and Ho Jun Lee contributed equally to this work as first author.

\section{Acknowledgment}

This study was supported by grant of Korea of Health \& Welfare, Republic of Korea (Project no. 090-091-3000-3033320 ).

\section{References}

[1] D. Hoegler, "Radiotherapy for palliation of symptoms in incurable cancer," Current Problems in Cancer, vol. 21, no. 3, pp. 135183, 1997.

[2] A. Caissie, L. Zeng, J. Nguyen et al., "Assessment of healthrelated quality of life with the European organization for research and treatment of cancer QLQ-C15-PAL after palliative radiotherapy of bone metastases," Clinical Oncology, vol. 24, no. 2, pp. 125-133, 2012.

[3] R. T. Hoppe, S. Fuks responses Strober, and H. S. Kaplan, “The long term effects of radiation on $\mathrm{T}$ and $\mathrm{B}$ lymphocytes in the peripheral blood after regional irradiation," Cancer, vol. 40, no. 5, pp. 2071-2078, 1977.

[4] H. E. Heier, "The influence of therapeutic irradiation on blood and peripheral lymph lymphocytes," Lymphology, vol. 11, no. 4, pp. 238-242, 1978.

[5] D. de Ruysscher, M. Waer, M. Vandeputte, R. Aerts, K. Vantongelen, and E. van der Schueren, "Changes of lymphocyte subsets after local irradiation for early stage breast cancer and seminoma testis: long-term increase of activated (HLA-DR+) T cells and decrease of "naive" (CD4-CD45R) T lymphocytes," European Journal of Cancer A, vol. 28, no. 10, pp. 1729-1734, 1992.

[6] K. Mori, T. Kido, H. Daikuhara et al., "Effect of Hochu-ekkito (TJ-41), a Japanese herbal medicine, on the survival of mice infected with influenza virus," Antiviral Research, vol. 44, no. 2, pp. 103-111, 1999.

[7] Y. Yamaoka, T. Kawakita, and K. Nomoto, "Protective effect of a traditional Japanese medicine, Bu-zhong-yi-qi-tang (Japanese name: Hochu-ekki-to), on the restraint stress-induced susceptibility against Listeria monocytogenes," Immunopharmacology, vol. 48, no. 1, pp. 35-42, 2000.

[8] M. Utsuyama, H. Seidlar, M. Kitagawa, and K. Hirokawa, "Immunological restoration and anti-tumor effect by Japanese herbal medicine in aged mice," Mechanisms of Ageing and Development, vol. 122, no. 3, pp. 341-352, 2001.

[9] T. Li, K. Tamada, K. Abe et al., "The restoration of the antitumor $\mathrm{T}$ cell response from stress-induced suppression using a traditional Chinese herbal medicine Hochu-ekki-to (TJ41:Bu-Zhong-Yi-Qi-Tang)," Immunopharmacology, vol. 43, no. 1, pp. 11-21, 1999. 
[10] S.-H. Kim, S.-E. Lee, H. Oh et al., "The radioprotective effects of Bu-Zhong-Yi-Qi-Tang: a prescription of traditional Chinese medicine," American Journal of Chinese Medicine, vol. 30, no. 1, pp. 127-137, 2002.

[11] S. Abe, S. Tansho, H. Ishibashi, N. Inagaki, Y. Komatsu, and H. Yamaguchi, "Protective effect of oral administration of a traditional medicine, Juzen-taiho-to, and its components on lethal Candida albicans infection in immunosuppressed mice," Immunopharmacology and Immunotoxicology, vol. 20, no. 3, pp. 421-431, 1998.

[12] Y. Ohnishi, H. Fujii, Y. Hayakawa et al., "Oral administration of a Kampo (Japanese herbal) medicine Juzen-taiho-to inhibits liver metastasis of colon 26-L5 carcinoma cells," Japanese Journal of Cancer Research, vol. 89, no. 2, pp. 206-213, 1998.

[13] I. Saiki, "HPLC analysis of Juzen-taiho-to and its variant formulations and their antimetastatic efficacies," Chemical and Pharmaceutical Bulletin, vol. 47, no. 8, pp. 1170-1174, 1999.

[14] A. Safwat, Y. Bayoumy, N. El-Sharkawy, K. Shaaban, O. Mansour, and A. Kamel, "The potential palliative role and possible immune modulatory effects of low-dose total body irradiation in relapsed or chemo-resistant non-Hodgkin's lymphoma," Radiotherapy and Oncology, vol. 69, no. 1, pp. 33-36, 2003.

[15] W. H. McBride, C.-S. Chiang, J. L. Olson et al., "A sense of danger from radiation," Radiation Research, vol. 162, no. 1, pp. $1-19,2004$.

[16] A. Uzawa, G. Suzuki, Y. Nakata, M. Akashi, H. Ohyama, and A. Akanuma, "Radiosensitivity of CD45RO+ memory and CD45RO- naive T cells in culture," Radiation Research, vol. 137, no. 1, pp. 25-33, 1994.

[17] C. Belka, H. Ottinger, E. Kreuzfelder et al., "Impact of localized radiotherapy on blood immune cells counts and function in humans," Radiotherapy and Oncology, vol. 50, no. 2, pp. 199204, 1999.

[18] A. Eric, Z. Juranic, N. Tisma et al., "Radiotherapy-induced changes of peripheral blood lymphocyte subpopulations in cervical cancer patients: relationship to clinical response," Journal of BUON, vol. 14, no. 1, pp. 79-83, 2009.

[19] M. R. G. O'Gorman and J. K. A. Nicholson, "Adoption of single-platform technologies for enumeration of absolute Tlymphocyte subsets in peripheral blood," Clinical and Diagnostic Laboratory Immunology, vol. 7, no. 3, pp. 333-335, 2000.

[20] K. A. Reimann, M. R. G. O’Gorman, J. Spritzler et al., "Multisite comparison of CD4 and CD8 T-lymphocyte counting by single- versus multiple-platform methodologies: evaluation of Beckman coulter flow-count fluorospheres and the tetraONE System," Clinical and Diagnostic Laboratory Immunology, vol. 7, no. 3, pp. 344-351, 2000.

[21] A. Kuroiwa, S. Liou, H. Yan, A. Eshita, S. Naitoh, and A. Nagayama, "Effect of a traditional Japanese herbal medicine, Hochu-ekki-to (Bu-Zhong-Yi-Qi Tang), on immunity in elderly persons," International Immunopharmacology, vol. 4, no. 2, pp. 317-324, 2004.

[22] S. H. Shin, S. Y. Chae, M. H. Ha et al., "Effect of Bu-Zhong-YiQi-Tang on B cell development," Journal of the Korean Society of Food Science and Nutrition, vol. 33, no. 2, pp. 271-277, 2004. 


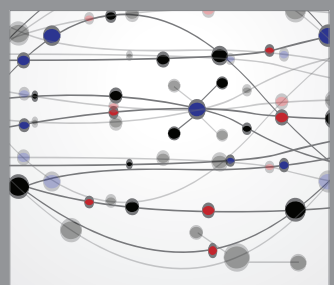

The Scientific World Journal
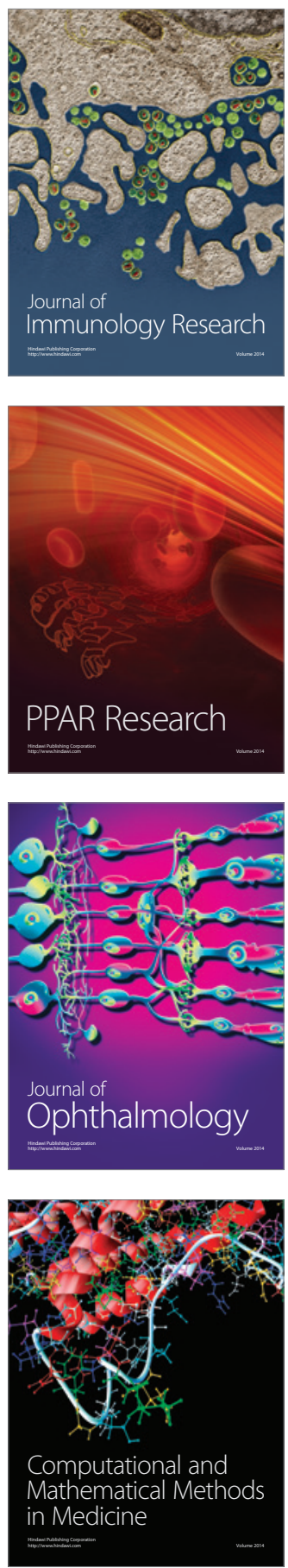

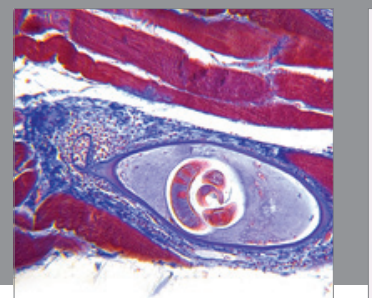

Gastroenterology

Research and Practice
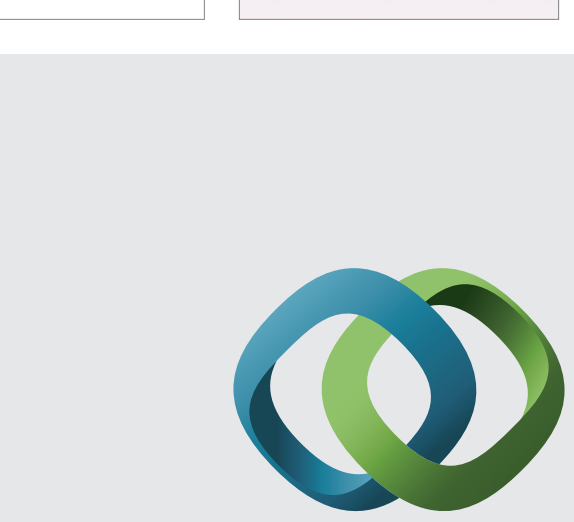

\section{Hindawi}

Submit your manuscripts at

http://www.hindawi.com
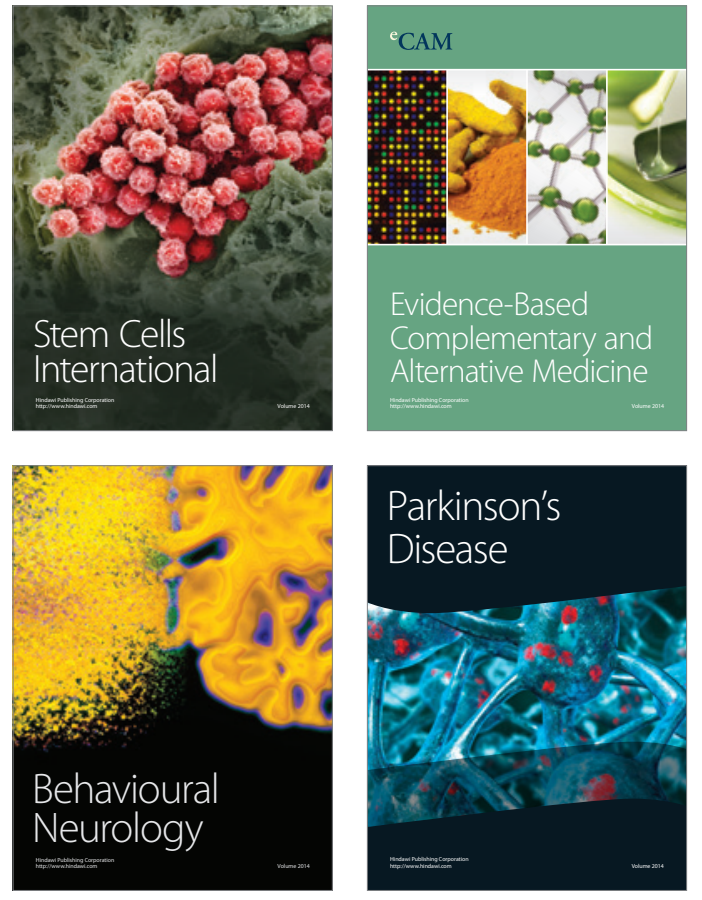
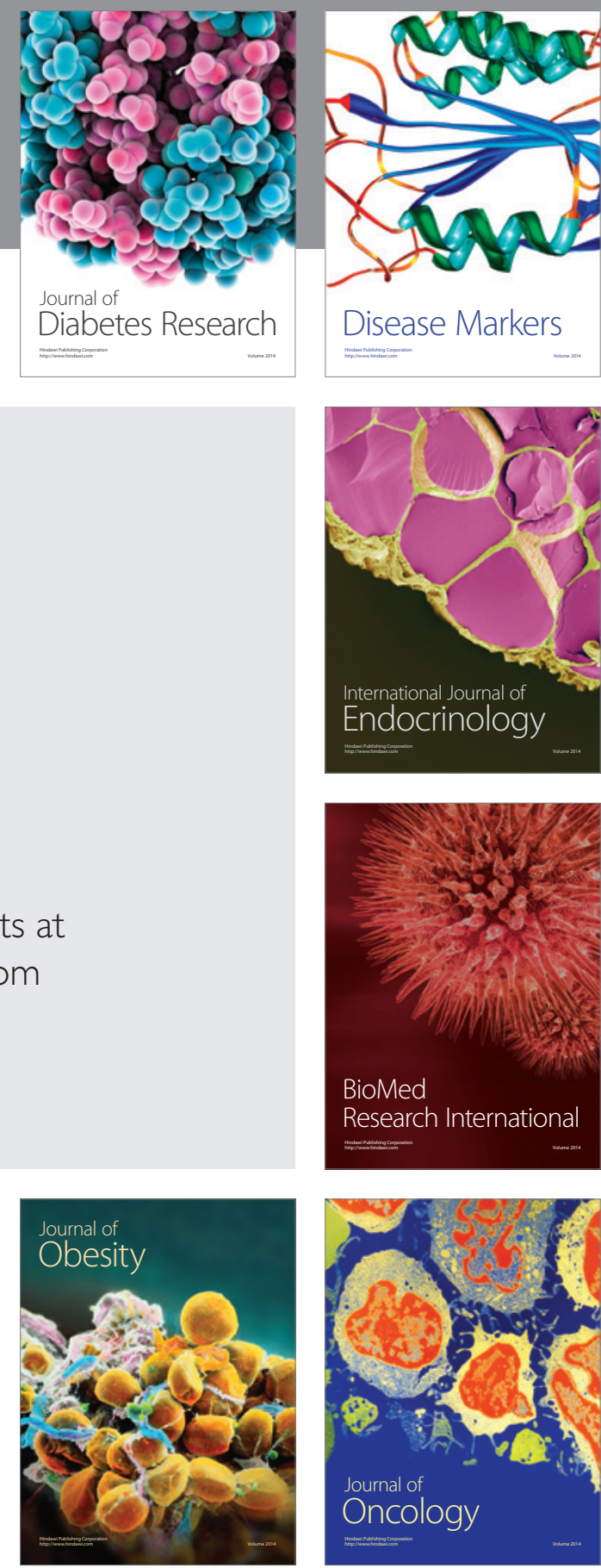

Disease Markers
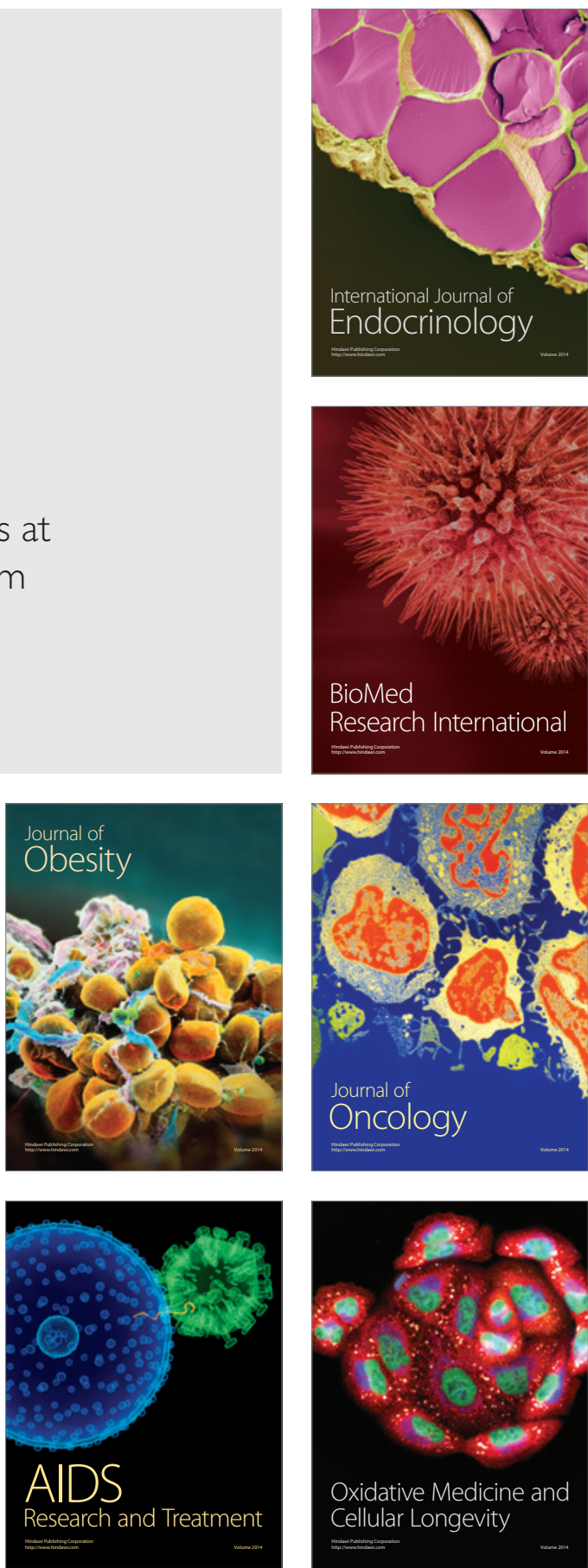